\title{
ALTERNATIVAS PARA A SAÚDE NO BRASIL
}

\author{
ALTERNATIVES FOR HEALTH AREA IN BRAZIL
}

Recebido em 16.05.2017. Aprovado em 19.06.2017

Avaliado pelo sistema double blind review

DOI: http://dx.doi.org/10.12712/rpca.v11i3.983

\section{Marcos Paulo Friedrich}

marcos.banrisul@gmail.com

IMED Business School, Passo Fundo/RS, BRASIL

\section{Renato Luiz da Silva}

renato.dasilva3622@gmail.com

IMED Business School, Passo Fundo/RS, BRASIL

\section{Julio Cesar Ferro de Guimarães}

juliocfguimaraes@yahoo.com.br

Universidade Federal de Pelotas (UFPEL)

\section{Kenny Basso}

bassokenny@gmail.com

IMED Business School, Passo Fundo/RS, BRASIL

\section{Resumo}

Com a resolução no 259 da Agência Nacional de Saúde Suplementar, o mercado de saúde privada acabou criando um produto alternativo, o cartão de descontos, que não se enquadra na fiscalização da ANS. Nesse contexto, o Centro Assistencial SM atua no mercado comum cartão de descontos para atendimentos ambulatoriais para a população das classes C e D. Novos desafios e propostas têm colocado o Centro Assistencial SM e seu gestor em um momento de importante decisão. A empresa precisa como irá expandir seus negócios e atuação neste mercado. Este caso de ensino foi elaborado para aplicação em cursos de graduação e pósgraduação, nas disciplinas de administração de serviços, gestão da qualidade; marketing, gestão estratégica e empreendedorismo. Nestes cursos, o caso de ensino por ser utilizado para reflexão e discussões sobre os temas como empreendedorismo, estratégias de mercado, contexto do setor da saúde no Brasil e marketing de produtos e serviços, além das dificuldades enfrentadas por gestores para tomar decisões estratégicas.

Palavras-chave: Empreendedorismo. Estratégias de mercado. Marketing. Planos de Saúde. Cartões de desconto.

\begin{abstract}
In 2011 the National Health Agency (NHA) issued Resolution No. 259 which regulates the deadlines for scheduling appointments, examinations and surgeries, seeking to better fiscalization of the private sector healthcare in Brazil. Because of this regulation, the private healthcare market created the discount card, which does not fit the supervision of NHA. In this context, the SM Assistance Center, which today offers a discount card for outpatient care for the population of the $\mathrm{C}$ and $\mathrm{D}$ classes, need to set up to diversify the products offered, also referring to classes $\mathrm{A}$ and $\mathrm{B}$. The objective of this teaching case is to provide reflection and discussions on topics such as entrepreneurship, marketing strategies, health sector context in Brazil and marketing products and services and the difficulties faced by managers to make strategic decisions.
\end{abstract}

Keywords: Entrepreneurship. Market strategies. Marketing. Health plans. Discount cards. 


\section{Introdução}

A crise financeira vivida pelo Brasil nos anos 90 somada a política neoliberal foram elementos que favoreceram a ampliação do setor privado na área da saúde, mais especificamente no modelo assistencial, com a ascensão dos planos de saúde e outros meios de acesso à saúde privada para a população. Nesta época, verificou-se um colapso nos serviços públicos oferecidos principalmente pelo Sistema Único de Saúde (SUS) e a consolidação de opções privadas, sendo o Estado um financiador desse processo, através da dedução no Imposto de Renda Pessoa Física e Jurídica (Reis, 2000).

Segundo a Agência Nacional de Saúde Suplementar (ANS), no setor privado existem cerca de 1.425 operadoras de saúde e elas são responsáveis por aproximadamente 70 milhões de consumidores, entre planos de assistência médica e odontológica, conforme discriminado na Figura 1. Estas operadoras em conjunto faturaram no ano de 2014 cerca de $\mathrm{R} \$ 127$ milhões o que representou um crescimento de 14\% em relação a 2013 e de 442\% entre 2004-2014. Estes dados demonstram que o setor não é apenas competitivo pelo grande número de operadoras presentes, mas também atrativo e lucrativo para os integrantes.

Figura 1. Panorama do setor da saúde no Brasil, 2015

\section{Panorama do setor}

\subsection{5 operadoras}

$\checkmark 921$ médico-hospitalares

$\checkmark 383$ exclusivamente odontológicas

$\checkmark 121$ administradoras de ben eficios

\section{Usuários}

$\checkmark$ 50,8 milhões em planos de assistência médica

$\checkmark 21,4$ milhões em planos exclu sivamente odontológicos

Fonte: Agência Nacional da Saúde Suplementar, 2015.

Em 2011, devido ao crescimento do número de reclamações sobre o atendimento destas operadoras privadas, a ANS lançou a resolução normativa $n^{\circ}$
259 que dispôs sobre a garantia de atendimento dos beneficiários de planos privados de assistência à saúde. Especificamente, esta nova resolução estabeleceu os prazos máximos para o agendamento de consultas, exames e cirurgias realizados através dos planos de saúde, não permitindo mais os longos prazos verificados até então.

A partir disso, 1.099 planos e 154 operadoras tiveram suas atividades suspensas para readequação e, destes, 924 conseguiram autorização para voltar ao mercado e comercializar novamente seus produtos e serviços. Porém, os planos que retornaram, tiveram de ajustar os preços muito acima da inflação oficial para atender as exigências legais e cumprir os novos prazos previstos. Esse aumento de preço impactou diretamente sobre os consumidores e subverteu os benefícios trazidos pela resolução $n^{\circ} 259$, gerando ainda mais reclamações. Desse modo, a ANS passou então a regular o aumento dos preços, definindo anualmente o percentual de reajuste sobre os planos individuais já em vigor. Esta situação dificultou o funcionamento destes planos gerando enormes prejuízos no segmento individual, fazendo com que as operadoras passassem a operar com grande foco nos planos coletivos e empresariais e tornando o preço de novas adesões individuais elevadíssimos já que os reajustes futuros seriam regulados pela ANS.

Em meio a esse cenário turbulento das operadoras privadas e a regulamentação mais rígida da ANS, o mercado da saúde privada passou a buscar alternativas para o segmento pessoa física/individual, como planos assistenciais programados, consórcios para cirurgias eletivas e cartões de desconto que, por suas características, não se enquadram na fiscalização da Agência Nacional de Saúde Suplementar - ANS. Os planos assistenciais programados, assim como os consórcios para cirurgias eletivas, estão principalmente relacionados a procedimentos não emergenciais, cuja realização pode ser agendada como, por exemplo, colocação de próteses, partos, cirurgias corretivas e implantodontia. Já os cartões de desconto, possuem convênios com profissionais e empresas da área da saúde para atendimento aos seus portadores, através de consultas, realização de exames e venda de produtos com preços inferiores aos praticados no mercado (até $70 \%$ menores).

Nesse contexto, o Centro Assistencial SM, que presta assistência social à população carente há 39 anos, vem buscando aproveitar o crescimento das classes $\mathrm{C}$ e D para criar alternativas de acesso desta população 
aos serviços privados de saúde. A principal opção oferecida no momento é a realização dos serviços de saúde através de um cartão de descontos para atendimentos ambulatoriais e exames. Atualmente o gestor do Centro, Sr. João Boll, há 14 anos à frente da empresa e com larga experiência na administração de serviços médicos, está enfrentando um dilema de crescimento provocado pelo aumento da demanda e pelo interesse de investidores externos que querem ampliar os produtos e serviços oferecidos para atendimento a um público-alvo diferente do atual.

O objetivo deste caso de ensino é proporcionar a reflexão e discussões sobre os temas como empreendedorismo, estratégias de mercado, contexto do setor da saúde no Brasil e marketing de produtos e serviços, além das dificuldades enfrentadas por gestores para a tomada de decisões estratégicas. Sugerese que este caso seja usado nos cursos de graduação e pós-graduação em disciplinas de administração de serviços, gestão da qualidade, marketing, gestão estratégica e empreendedorismo.

\section{O Centro Assistencial SM}

O Centro Assistencial SM iniciou suas atividades em 1976 no município de Passo Fundo no estado do Rio Grande do Sul, com o objetivo de prestar serviços de assistência social e acompanhamento de famílias carentes que apresentavam necessidades não atendidas pelos órgãos públicos. Nesta época, o Centro organizava eventos como feiras e brechós, com a finalidade de arrecadar recursos para construção e manutenção de creches, para incentivo a cursos de profissionalizantes e para geração de trabalho e renda para famílias de baixa renda. Seu quadro de funcionários à época contava com 03 colaboradores, sendo 1 contratado e 2 voluntários não remunerados.

Em 1995, a entidade passou a oferecer também serviços na área da saúde como psicologia, fisioterapia e massoterapia para pacientes que não tinham acesso a esses serviços na rede pública. Os profissionais da saúde eram terceirizados e realizavam atendimentos no espaço físico do Centro. Eles eram pagos pela própria entidade para cada consulta realizada e o custo era repassado aos pacientes, representando um preço diferenciado do mercado, com custo reduzido e possibilidade de acesso para pessoas de baixa renda.

Nos anos 2000, a precariedade na saúde no Brasil se agravou, ampliando a necessidade de atendimentos na área da saúde como os serviços oferecidos pelo Centro. A partir de então ele passou a contar com médicos de diversas especialidades (clínico geral, endocrinologista, cardiologista, ginecologista, etc.) e com a possibilidade de realização de exames como ultrassom e eletrocardiograma. Os serviços continuavam a ser oferecidos no espaço físico do Centro, que já começava a apresentar limitações. Nesta época o Centro contava com 2 funcionários contratados, 9 profissionais da saúde e cerca de 6 voluntários não remunerados.

Sem condições de ampliar seu número de atendimentos devido a restrições de espaço físico, em 2009 o Centro Assistencial SM resolveu criar uma rede de assistência nas áreas médica, odontológica, laboratorial, farmacológica e de exames de imagem, credenciando profissionais para atendimentos externos. Os contatos com empresas e profissionais que já atuavam neste ramo apresentaram enorme aceitação e receptividade devido ao histórico de atuação do Centro e sua grande credibilidade na assistência social e nos serviços de saúde já oferecidos. Deste modo, as consultas eram agendadas e encaminhadas pelo Centro, porém realizadas nos consultórios próprios dos profissionais, mantendo o preço reduzido para aqueles cujo agendamento fosse realizado pelo Centro.

Inicialmente surgiram dificuldades para que os pacientes encaminhados pelo Centro se identificassem quando da chegada aos consultórios externos. Esse contratempo inicial, juntamente com a situação da saúde no Brasil, deu origem ao Cartão do Centro Assistencial SM. Esse cartão poderia ser adquirido pelo interessado e lhe garantia descontos em procedimentos particulares em todos os profissionais credenciados. O Cartão é vendido até os dias atuais em pacotes familiares, com renovação anual, apresentando um custo de $\mathrm{R} \$ 150,00$ por ano para cada 04 pessoas. Os serviços oferecidos incluem agendamento e acompanhamento das consultas com facilidade de acesso e agilidade, tornando-se um diferencial tanto em termos de preço baixo quanto em qualidade de atendimento.

Nos primeiros meses de lançamento do cartão (2010), o Centro Assistencial SM apresentou um faturamento de aproximadamente $\mathrm{R} \$ 8.000,00 /$ mês $(\mathrm{R} \$ 96.000,00 /$ ano) oferecendo somente 9 profissionais da saúde credenciados. Em 2015, após cinco anos de comercialização, o Centro Assistencial SM faturou cerca de R $\$ 95.000,00 /$ mês com cerca de 42.300 
cartões emitidos. O Sr. João Boll, acredita que este crescimento se deve, principalmente, a qualidade dos serviços prestados que geraram grande divulgação boca-a-boca, pois argumenta que o investimento em publicidade e propaganda foi baixo e pouco expressivo. O Centro conta atualmente com 14 funcionários e 147 credenciados, incluindo laboratórios, clínicas e profissionais de diversas áreas da saúde como fonoaudiologia, nutrição, psicologia, exames diversos, odontologia, fisioterapia, entre outros, . abrangendo todas as especialidades médicas à exceção de pediatria e gastrenterologia.

O crescimento de vendas do cartão entre 2010 e 2015 permitiu a ampliação do espaço do Centro com a construção de uma policlínica com cerca $2.000 \mathrm{~m}^{2}$ e de 32 consultórios para que os profissionais credenciados realizassem seus atendimentos no espaço próprio do Centro. Para estes atendimentos, o profissional recebe todo o suporte necessário, não tendo custos com funcionários, equipamentos, materiais ou móveis. Estes custsos são absorvidos pelos Centro. Desta forma, a realização das consultas e exames apresenta um custo cerca de $50 \%$ menor que nos consultórios ou clínicas particulares e permite aos pacientes agendar consultas com especialistas com prazo médio de sete dias enquanto no SUS ou em planos de saúde este prazo seria entre 30 a 60 dias.

Desde o princípio, o público alvo para o produto eram as classes sociais de baixa renda que não tinham acesso aos planos de saúde convencionais e que dependiam exclusivamente do SUS. Porém, alguns fatos como: a ampliação da renda e da capacidade de compra das classes $\mathrm{C}, \mathrm{D}$ na primeira década do século XXI; o preço reduzido do cartão do Centro Assistencial em comparação com a mensalidade dos planos de saúde; o fato de ter apenas um pagamento anual e não mensalidades; o atendimento diferenciado na policlínica e a facilidade para agendamento de consulta e exames; transformaram o Cartão em uma alternativa acessível à população e em um produto com alta taxa de crescimento de vendas desde o seu lançamento.

\section{O dilema do crescimento}

Em 2015, a ampliação no volume de vendas do Cartão e a inauguração da policlínica despertaram o interesse de investidores do setor que procuraram a administração do Centro Assistencial SM para fazer uma proposta ao Sr. João. Seu objetivo era financiar a criação de novas linhas de produtos que pudessem atender uma fatia maior da população. Seu projeto envolvia a criação de novas modalidades de cartões: cartão funeral, cartão VIP e cartão premium, com pagamentos mensais ao invés de pagamento único anual e com preços de $\mathrm{R} \$ 150,00 / \mathrm{ano}, \mathrm{R} \$ 600,00 /$ ano e $\mathrm{R} \$ 960,00 /$ ano, com serviços e preços diferenciados daqueles do cartão atual.

O cartão funeral ofereceria a cobertura das despesas de funeral até o valor de $\mathrm{R} \$ 2.450,00$. Seu custo de $\mathrm{R} \$ 150,00 /$ ano incluiria quatro cartões (quatro beneficiários), porém apresentaria o limitador da cobertura de apenas um funeral por ano para cada pacote de quatro cartões. O cartão VIP permitiria aos consumidores o acesso à mesma rede credenciada do cartão atualmente comercializado, porém com descontos maiores nas consultas e exames, apresentando como teto para o preço dos serviços o valor de $R \$ 25,00$ por consulta. Já o cartão premium, apesar do custo superior ao do cartão atual, teria como diferencial o acesso a consultas e exames gratuitos, sem nenhum custo adicional para os portadores do cartão. Além do diferencial de preço, a proposta dos cartões VIP e premium somente permitem adesão individual e também possuem forma de pagamento alternativa, podendo ser parcelada em até 6 vezes (VIP) e até 12 vezes (premium).

A proposta realizada pelos investidores inclui o custeio de todas as despesas de investimento para o lançamento dos cartões, porém, como retorno ao seu capital eles ficariam com $10 \%$ de toda a receita de venda do Centro Assistencial, não só dos novos cartões como também daquela modalidade já existente, que apresenta faturamento crescente e perspectivas de ampliação para os próximos anos.

O Sr. João acredita que essa mudança na estrutura do Centro Assistencial pode representar a consolidação do produto cartão, através da diversificação dos produtos oferecidos, da ampliação do público alvo abrangendo também as classes A e B e da possibilidade de aumentar muitas vezes o faturamento, considerando que os cartões com pagamentos mensais seriam individuais e a população de alta renda teria de adquirir um para cada familiar.

Por outro lado, o posicionamento estratégico da empresa atualmente está centrado no mercado de média-baixa e baixa renda sendo que seu grande diferencial competitivo é o fato de não ter mensalidades 
e de que, além da adesão ao cartão $(\mathrm{R} \$ 150,00)$, o consumidor só tem custos quando efetivamente utiliza o produto. Já com as novas modalidades de cartões, os clientes teriam custos mensais que, apesar de serem mais baixos que os de um plano de saúde, permitiriam que o produto, na prática, fosse confundido com planos de saúde devido à forma de pagamento, porém com a desvantagem de serem somente ambulatorial, enquanto muitos planos de saúde incluem internação hospitalar.

Outro fator importante é o atendimento. A estrutura atual de secretaria na policlínica e de agendamento de consultas não permite ampliação e/ou possibilidade de diferenciação de espaço ou forma de recepção para os consumidores de um produto ou de outro, fazendo com que a população de alta e baixa renda sejam atendidos pelo mesmo canal o que pode acarretar em descontentamento pelos consumidores dos produtos com maior valor agregado.

Caso o Sr. João Boll optasse por não aceitar a proposta, os investidores haviam deixado claro que iriam propor a outras empresas do setor esse projeto ou então iriam criar uma nova empresa com o mesmo segmento e que atendesse todos os públicos, das classes $\mathrm{A}$ até a $\mathrm{D}$. Nesse sentido, o Sr. João teria então que decidir entre:

a) desenvolver novos produtos: diversificar as modalidades de cartões oferecidos e de descontos proporcionados, possibilitando inclusive consultas $\mathrm{e}$ exames gratuitos e ampliando os preços e, consequentemente, o faturamento. Isso implicaria na implantação de um Processo de Desenvolvimento de Novos Produtos (PDNP) que permitisse explorar corretamente as demandas de mercado. Esta opção não acarretaria em custos, pois estes seriam custeados pelos investidores externos, porém não haveria garantia de ampliação da lucratividade e parte da receita atual teria de ser dividida com os novos sócios.

a) ampliar os tipos de consumidores e/ou mercados: reposicionar a empresa no mercado exigiria forte investimento em estudo de mercado e desenvolvimento dos vendedores e atendentes. Explorar novos mercados através da modificação de produtos e/ou de público alvo pode ampliar fortemente a receita. Porém a expectativa de atendimento e a percepção de qualidade nos serviços para públicos com renda mais elevada e/ou que adquire produtos com maior valor agregado é diferente daqueles com baixa renda e que adquirem o cartão mais barato. Isso poderia acarretar em reclamações e insatisfação com os novos produtos.

\section{Notas de ensino \\ Utilização Recomendada}

Este caso de ensino foi elaborado para aplicação em cursos de graduação e pós-graduação, nas disciplinas de administração de serviços, gestão da qualidade; marketing, gestão estratégica e empreendedorismo.

Sugere-se que o professor, ao aplicar o caso de ensino, promova a leitura e discussão em sala de aula, portanto os seguintes passos podem ser seguidos:

a) inicialmente o professor deve reunir os alunos em grupos de até cinco pessoas;

a) solicitar aos alunos que realizem a leitura, em sala de aula, do Caso de Ensino (Introdução, O centro assistencial SM, O dilema do crescimento);

b) para reforçar o entendimento, é aconselhável, que após a leitura o professor faça uma apresentação interativa do caso, evidenciando e questionando os alunos sobre com os principais elementos históricos, contexto e problemas que o protagonista do caso está vivenciando. Este procedimento estimula que os alunos tenham um entendimento compartilhado da situação.

c) posteriormente, os alunos são convidados a discutir nos pequenos grupos e responder as questões do caso (Sugestão de Questionamentos para a Discussão). Todas as respostas dos alunos devem considerar as opiniões dos participantes do grupo, entretanto é fundamental utilizar como base o referencial teórico disponível no Caso (POSIBILIDADES PARA ANÁLISE DO CASO), pois as respostas devem unir a 
prática aos elementos teóricos. O professor pode escolher apenas algumas das questões sugeridas no caso, o que depende do objetivo de aprendizagem que o professor está buscando com a aplicação do caso, enquanto metodologia ativa de ensino.

d) os grupos devem entregar as respostas por escrito. Sugere-se que a discussão das respostas ocorra em grupos, para que seja obtido um conhecimento compartilhado, entretanto, será mais proveitoso se cada aluno escrever a sua resposta. Esta prática tem o objetivo de o aluno materialize o conhecimento adquirido, expressando-o por meio da escrita.

e) finalmente, o professor pode promover um fechamento da atividade, por meio da discussão com a turma inteira. Permitindo que os alunos possam se expressar e difundir as diferentes soluções encontradas para o mesmo problema.

f) nota-se ainda, que o professor deve avaliar as respostas sob o prisma de que os alunos devem responder com profundidade e com embasamento teórico, desta forma a avaliação do caso de ensino busca desenvolver e identificar a capacidade do aluno em encontrar soluções em equipe $e$ relacionar as decisões ao arcabouço teórico da área da Administração.

\section{Objetivos de Aprendizagem}

Através da análise do caso sobre o Centro Assistencial SM e será possível abordar e discutir alguns tópicos relativos ao processo de ensino-aprendizagem na formação de administradores, por exemplo:

a) discussão acerca do posicionamento estratégico da empresa no mercado em que atua e quais seus diferenciais competitivos;

b) estudo das alternativas de estratégias a serem adotadas frente ao cenário exposto de mercado global e local, bem como formulação do plano de ação para cada cenário;

c) decisão relacionada ao público-alvo da empresa, qual a demanda existente para esse público e quais as vantagens e desvantagens da ampliação ou mudança;

d) discussão acerca do perfil do gestor e do empreendedorismo nas empresas da área da saúde;

e) estudo das possibilidades da ampliação do número de produtos/serviços oferecidos e dos impactos de cada escolha sobre o preço/praça/produto/promoção atuais;

f) análise da percepção de qualidade em produtos e serviços, como mensurar a qualidade em intangíveis e como ampliar a qualidade percebida.

\section{Sugestão de Questionamentos para a Discussão}

1) Faça uma análise do mercado da saúde no Brasil utilizando o modelo das cinco forças de Porter (1979). Quais as principais variáveis envolvidas em cada uma das cinco forças?

1) Quais os diferenciais competitivos dos produtos e serviços oferecidos pelo Centro Assistencial SM? Estes diferenciais podem se tornar vantagens competitivas sustentáveis?

2) Como o paradigma da qualidade dos serviços é utilizado pelo Centro Assistencial $\mathrm{SM}$ ? Quais os riscos para a percepção de qualidade do posicionamento assumido pela empresa?

3) A partir do caso apresentado e da literatura existente, o sr. João deve escolher qual estratégia: crescer ou manter? Escolhida opção entre crescer ou manter, defina as possíveis estratégias que a empresa poderia adotar.

4) A inovação traz consigo características de diferenciação (Drucker, 2002, Schumpeter, 1982) e, ao mesmo tempo, riscos e incertezas sobre a aceitação dos novos produtos/ serviços/processos pelo mercado. Nesse contexto, quais os pontos que devem ser considerados pela empresa antes de decidir inovar? 
5) Segundo Kotler e Keller (2006), o Mix de Marketing formado pelos 4 P's é uma excelente ferramenta para alcançar estratégias de mercado. Sendo assim, faça uma análise e descreva como está definido o Mix de Marketing do Centro Assistencial $\mathrm{SM}$ e como ele poderia se alterar em caso da inclusão dos novos cartões.

\section{Posibilidades para análise do caso}

\section{Modelo das cindo forças de Porter}

Em meio à turbulência encontrada no setor de saúde brasileiro no início do século XXI, o Centro Assistencial SM buscou alternativas para se posicionar frente a este cenário, com o objetivo obter um diferencial competitivo junto aos demais concorrentes. O modelo das cinco forças de Porter (1979) pode ser utilizado para compreender melhor este contexto, bem como a posição adotada pelo Centro.

Porter (1979) popularizou a utilização do modelo SPC (Structure-Conduct-Performance) no campo da estratégia competitiva, através do modelo das forças competitivas, e suas definições estratégicas genéricas de posicionamento, através da liderança no custo e na diferenciação. Sendo assim, a estratégia competitiva, segundo o autor, é a busca de uma posição competitiva favorável em uma indústria em relação a seus concorrentes. Duas questões centrais baseiam a escolha estratégica competitiva:

a) atratividade das indústrias, em termos de rentabilidade a longo prazo e os fatores que determinam esta atratividade, isto é, o quanto uma indústria é rentável a longo prazo;

b) determinantes da posição competitiva relativa dentro de uma indústria. Neste contexto, a estratégia competitiva não apenas responde ao meio ambiente, mas tenta modificar este meio em seu favor para obtenção de vantagens e diferenciais (Porter, 1989).

Ao analisar a atratividade da indústria, através da compreensão das regras da concorrência, o autor sugere um modelo de cinco forças competitivas. Estas cinco forças determinam a rentabilidade da indústria, pois influenciam os preços, os custos e o investimento necessário para as empresas em uma indústria com alta competitividade. O modelo das cinco forças (Porter, 1989), descrito abaixo, analisa as seguintes características externas a firma:

1) Ameaça de novos concorrentes (Barreiras à entrada): analisada por meio de evidências sobre economia de escala; diferenciação do produto; imagem de marca; necessidade de fundos; custos de mudanças; acesso aos canais de distribuição; know-how; acesso favorável a matérias primas; curva de experiência; políticas do governo e retaliação esperada.

2) O poder de negociação dos compradores: analisada por meio de evidências sobre concentração de compra; volume de compras; inexistência de diferenciação; custos de mudança reduzidos para o cliente e elevados para a empresa; ameaça de integração à montante; informações disponíveis; produtos substitutos.

3) Poder de negociação dos fornecedores: analisada por meio de evidências sobre concentração de fornecedores; inexistência de produtos substitutos; diferenciação de entrada; custos de mudança de fornecedores; importância do volume de fornecedores; custo em relação ao total comprado na indústria; custo de integração a jusante.

4) Ameaças de produtos ou serviços substitutos: analisada por meio de evidências sobre_a relação preço vs rendimento/ desempenho dos produtos; custos de mudança de produtos ou serviço; propensão do comprador para aquisição de produtos substitutos.

5) Rivalidade entre as empresas existentes (Crescimento da indústria): analisada por meio de evidências sobre o número de concorrentes; custos fixos elevados; reduzida diferenciação; custos de mudança; sobrecarga de produção intermitente; diversidade de concorrentes; importância estratégica do negócio; barreiras à saída: ativos específicos; custos fixos à saída; relações estratégicas; barreiras emocionais; restrições sociais/ governamentais. 
A posição relativa de uma empresa dentro de sua indústria é determinante para a sua rentabilidade potencial, sendo sustentado por sua estratégia competitiva genérica (Porter, 1989). O autor identificou e definiu três estratégias genéricas, sendo assim definidas:

a) liderança em custo: exige normalmente que a empresa seja a líder em custos, conseguindo assim se tornar o produtor de mais baixo custo em sua indústria;

b) diferenciação: exige que a empresa escolha atributos que a diferencie de seus concorrente, procurando assim ser a única em sua indústria;

c) foco: esta estratégia difere-se das demais, pois está baseada na escolha de um segmento específico dentro da indústria, onde a empresa irá atuar, visando assim atender apenas a uma parte restrita do mercado.

\section{Posicionamento de mercado (SWOT)}

Para auxiliar o Sr. João a compreender o ambiente no qual está inserido, fazendo assim um adequado planejamento estratégico, dando ao mesmo condições de avaliar corretamente a situação do Centro Assistencial SM e de sua capacidade de competição no mercado, identificando seus pontos fortes e fracos, bem como as suas oportunidades e ameaças, poderá ser utilizado a matriz SWOT.

A matriz SWOT [Strengths (forças), Weaknesses (fraquezas), Opportunities (oportunidades) e Threats (ameaças)], foi desenvolvida inicialmente por Kenneth Andrews e Roland Christensen. Essa técnica contribui para formação de estratégias competitivas através da identificação dos pontos fortes e pontos fracos, que são os fatores internos da organização, e as oportunidades e ameaças, que são os fatores externos da organização (Silveira, 2001). A utilização deste tipo de análise permite uma avaliação do ambiente interno (forças e fraquezas) com foco em integração de processos, padronização de processos, eliminação de redundâncias e foco na atividade principal da empresa. Já no que tange ao ambiente externo (oportunidades e ameaças), a análise SWOT verifica a confiabilidade dos dados levantados, redução de falhas e informações disponíveis em tempo real para tomada de decisão.
Para excelente realização de uma análise do tipo SWOT, primeiramente é preciso colher e absorver informação secundária sobre a empresa que se está analisando e sobre o setor econômico que integra (Miller, 2002,). Esta técnica de análise, segundo Wright, Koll e Parmell (2000) tem como objetivo possibilitar que a empresa se posicione para tirar vantagem de determinadas oportunidades do ambiente e evitar ou minimizar ameaças ambientais.

Após a elaboração da lista dos de fatores, utilizandose o critério de importância e de influência no cumprimento dos objetivos da organização, são ordenados os pontos fortes e fracos, oportunidades e ameaças e incluídos na matriz SWOT, possibilitando assim um consenso e uma conclusão do que é realmente importante e deve ser considerado pela empresa.

A avaliação de mais de um fator simultaneamente permite que seja realizado o que se chama de análise SWOT cruzada. Boone e Kurtz (1998) afirmam que a junção de um ponto forte interno com uma oportunidade externa produz uma situação conhecida como alavancagem para a organização, isto é, pontos fortes $v s$ oportunidades resultam em estratégias ofensivas de exploração do mercado. Já pontos fracos vs ameaças denotam a necessidade de estratégias defensivas com alterações profundas. Dessa maneira, um problema existe quando as ameaças do ambiente atacam um ponto fraco da organização, pois as limitações internas impedem a organização de capitalizar oportunidades. Uma ameaça ambiental a um ponto forte corrente da organização é chamada de vulnerabilidade.

Ainda existe a possibilidade de se avaliarem pontos fortes e ameaças, que denotam a necessidade de alterar o ambiente em favor da empresa, enquanto que a análise dos pontos fracos e oportunidades exigem uma estratégia com esforços para um melhor aproveitamento das oportunidades verificadas.

Através desta análise a organização poderá confirmar e até mesmo ratificar a missão da organização impedindo assim possíveis dispersões, incertezas e indefinições dos processos (Silveira, 2001). Sendo assim, Lima, Sapiro, Vilhena e Gangana (2003) afirmam que o gestor deve procurar identificar os pontos fortes existentes e desenvolver outros que permitam a organização aproveitar as novas oportunidades que surgem no mercado. Essas oportunidades referemse à comparação com a concorrência, a qual será 
determinante para definir os caminhos futuros da organização.

As oportunidades e ameaças enfrentadas pelas organizações podem gerar vantagens competitivas, seja pelo posicionamento de mercado (Porter, 1990) ou pela utilização de recursos estratégicos que levam ao um diferencial competitivo entre as organizações (Barney, 1991). A vantagem competitiva pode resultar da inovação, traduzidas em patentes de novos produtos, utilização de novos processos, ações inovadoras de marketing e/ou a implementação de inovações organizacionais, desta forma levando a organização a uma posição vantajosa em relação à concorrência (Guimarães, Severo, \& Vieira, 2015).

\section{Lealdade dos clientes}

O desafio da sobrevivência em um mercado cada vez mais competitivo e dinâmico, força as empresas a adotarem novas maneiras de gestão, buscando compreender as necessidades e desejos do consumidor, promovendo assim a satisfação dos mesmos. Através deste contexto, o Centro Assistencial SM precisa compreender quais são estas necessidades e desejos de seus consumidores, tanto os atuais quanto os potencias, buscando obter um diferencial competitivo frente a concorrência. Além disso, a lealdade dos seus consumidores pressupõe uma intenção de recompra e, como os cartões apresentam validade de apenas um ano, a construção de uma relação de lealdade fará com que o percentual de renovações seja cada vez mais expressivo.

Nesse sentido, compreender exatamente quais são estas expectativas do cliente não é uma tarefa fácil, pois as mesmas são construídas a partir de diversas fontes, como "boca-a-boca", propagandas, experiências anteriores e o nível de exigência com o qual o cliente irá comparar o desempenho percebido do serviço. Para que se obtenha uma fidelização destes clientes, o serviço percebido deve ser superior ao esperado, porém se isto não ocorrer, a empresa corre o risco de perder este cliente, pois irá decepcioná-lo (Kotler \& Keller, 2006; Loverlock, 2006).

Oliver (1997) definiu a satisfação como a resposta de plenitude do consumidor, ou seja, um julgamento que um produto ou serviço tem como característica, pelo fato de ter provido ou estar provendo um nível agradável de plenitude relacionada ao consumo.
Porém estudos empíricos realizados indicam que a relação entre satisfação e lealdade não é linear e muito menos simples, pois um alto nível de satisfação nem sempre é suficiente para gerar comportamentos de lealdade, e esta por vezes é motivada pelos custos de mudança (Jones \& Sasser, 1995; Oliver, 1997).

Além da satisfação, Sirdeshmukh et al. (2002) definem em seu modelo teórico para construção da lealdade, que este construto tem como antecedente também a confiança dos consumidores, confiança tanto nas políticas e práticas da empresa como nos funcionários de linha de frente. A confiança, por sua vez, é entendida por estes autores como a expectativa que o consumidor possui de que o prestador de serviço irá cumprir suas promessas.

Portanto, pode-se afirmar que a construção de uma relação de confiança é antecedente do direto da lealdade dos consumidores que determina tanto o boca-aboca positivo como a intenção de recompra (dos Santos \& Basso, 2012). No caso específico do Centro Assistencial SM, a lealdade dos consumidores tem efeito direto sobre os resultados de vendas de cartões considerando que o principal meio de divulgação do cartão é o boca-a-boca e, que as renovações são anuais, necessitando uma forte intenção de recompra para manter os clientes fidelizados ao produto. Também convém citar, que a segmentação dos consumidores também é um fator importante, face a possível relação entre traços de personalidade dos clientes e a propensão ao boca-a-boca (Basso, Laimer, \& Baseggio, 2015).

\section{Capacidade de inovação}

A abordagem conceitual de inovação obteve maior espaço a partir da obra de Schumpeter, na publicação do livro: Teoria do Desenvolvimento Econômico, onde o autor descreve a inovação como a ação de inovar, de criar processos que promovam a ruptura no sistema econômico, permitindo o surgimento de novidades (Schumpeter, 1934). O autor, em sua obra define o conceito de "destruição criadora", que ocorre nas economias capitalistas, onde o desenvolvimento econômico é orientado pelo impacto das inovações tecnológicas, onde a inovação é caracterizada por um processo de criação do novo perante a destruição do obsoleto, contradizendo o conceito do equilíbrio da economia, como é descrito na teoria neoclássica. 
As empresas recebem pressões competitivas, relacionadas à adaptação rápida e contínua a um complexo e dinâmico ambiente, altamente interligado de forma global, neste sentido, prementes desafios incluem ainda manter o ritmo com ciclos mais curtos de vida do produto, incorporando várias tecnologias para a concepção de novos produtos e serviços (Guimarães, Severo, \& Vieira, 2015).

Hurley e Hult (1998) afirmam que existe forte ligação empírica entre inovação organizacional e capacidade de inovação, assim como o argumento teórico de que a inovação é um mecanismo para que as organizações se adaptarem em ambientes dinâmicos. Wang e Ahmed (2004) definem inovação organizacional como a capacidade de inovação global da organização, através da introdução de novos produtos para o mercado, ou abertura de novos mercados, através da combinação de orientação estratégica com o comportamento e processo inovador.

Os resultados referentes aos antecedentes de inovação sugerem que pesquisadores interessados em próatividade e capacidade de resposta aos mercados devem encarar a cultura como um complexo sistema de crenças que afetam o comportamento organizacional (Hurley \& Hult, 1998). Neste contexto, a inovação pode ser introduzida por meio de mudanças capazes de criar melhorias de desempenho organizacional (Drucker, 2002). Sendo assim, um forte foco proativo nas necessidades emergentes dos clientes e em novas tecnologias, levam a um portfólio de novos produtos com maior novidade e tecnologia, o que aumenta o desempenho da empresa (Talke, Salomo, \& Kock, 2011).

Wang e Ahmed (2004) através de uma extensa revisão da literatura identificaram cinco dimensões de inovação global em uma organização, podendo ser assim definidas:

a) capacidade de inovação de produto: a inovação de produtos pode ser definida como a novidade e o significado de novos produtos introduzidos no mercado em tempo hábil;

b) capacidade de inovação de mercado: a inovação de mercado pode ser classificada como a novidade das abordagens adotadas pelas empresas para entrar e explorar o mercado-alvo;

c) inovação de processos: a inovação de processos analisa a introdução de novos métodos de produção, novas abordagens de gestão e novas tecnologias que podem ser usadas para melhorar os processos de produção e de gestão. Sendo assim, a inovação de processo é um imperativo na capacidade de inovação global, sendo a capacidade de uma organização para explorar, recombinar e reconfigurar os seus recursos e capacidades para cumprir a exigência de inovação da produção, se tornando fundamental para o sucesso organizacional;

d) inovação comportamental: cultura inovadora serve como um catalisador de inovações, enquanto que a falta dela atua como bloqueador de inovações, portanto a inovação comportamental é um fator fundamental que ressalta os resultados inovadores. A inovação comportamental pode estar presente em diferentes níveis: indivíduos, equipes e gestão, permitindo assim a formação de uma cultura de inovação através da receptividade interna para novas ideias.

e) capacidade de inovação estratégica: a orientação para a inovação estratégica de uma empresa visa descobrir e satisfazer as necessidades emergentes dos clientes, através de soluções tecnológicas inovadoras, sendo crucial para o desempenho. Anderson e Markides (2007) afirmam que os inovadores estratégicos bem sucedidos criam produtos e serviços que são adaptados às necessidades específicas de clientes, distribuidores ou ambos. Hamel (1998) afirma que os inovadores estratégicos olham para além das fronteiras convencionalmente definidas pela concorrência, a fim de descobrir espaços de mercado inexplorados, buscando assim valor radicalmente superior, o que torna a concorrência irrelevante.

As inovações são resultado de capacidades dinâmicas, com a interação de diferentes recursos, portanto é fundamental que a organização avalie os impactos sociais e ambientais decorrentes das inovações de processo, produto, organizacional e marketing, pois estes fatores são entendidos como atributos da vantagem competitiva, os quais são co-criados por 
indivíduos da organização ao interagirem com outros Stakeholders (De Guimarães et al., 2014; Severo et al., 2015).

\section{Estratégias de marketing}

O Centro Assistencial SM tem a possibilidade de ampliar o seu público alvo, passando assim a atender as classes sociais A e B, além das já atendidas classes C e D. Diante deste contexto, se faz necessário analisar a questão da segmentação de mercado, bem como as estratégias de marketing que serão adotas pelo Centro Assistencial SM com intuito de manter ou modificar seu posicionamento estratégico.

Assim sendo, uma empresa que deseja posicionar-se perante o mercado de determinada maneira, deverá desenvolver o composto de marketing para atingir a esses objetivos específicos (Las Casas, 2006). Churchill e Peter (2005, p. 20) afirmam que onde o "composto de marketing é uma combinação de ferramentas estratégicas usadas para criar valor para os clientes e alcançar os objetivos da organização”.

Lambin (1998) afirma que o marketing estratégico apoia-se na análise das necessidades dos indivíduos e organizações, e tem como função seguir a evolução do mercado de referência, identificando os diferentes produtos-mercado, bem como os segmentos atuais ou potenciais, compreendendo através destas diversidades as necessidades a satisfazer. Kotler e Keller (2006) relacionam a formulação de estratégias de marketing dentro de um processo de planejamento, implementação e controle do marketing estratégico.

A segmentação de mercado é utilizada pelas organizações como um recurso estratégico, podendo ser descrita como o ato de dividir o mercado total de um produto ou serviço em diversos grupos menores, sendo estes internamente homogêneos (Etzel, Walker \& Stanton, 2001). Assim sendo, o consumidor de um segmento é similar (tanto quanto possível), em certas características, aos demais elementos do segmento, assim como deve ser diferente (o mais possível) dos consumidores dos outros segmentos (Webster Jr., 1994). Kotler e Keller (2006)seguem por esta linha de raciocínio ao afirmarem que um segmento consiste de um grupo de consumidores (finais ou organizações) com preferências similares. Por exemplo, Basso e Espartel (2015) utilizam tanto a personalidade e a lealdade de clientes para estabelecer bases de segmentação psicográficas e comportamentais de clientes.

De um modo geral, os elementos que uma empresa necessita trabalhar para elaborar e gerenciar estratégias de marketing estão presentes na análise do ambiente, na identificação das necessidades dos clientes e oportunidades no mercado, na segmentação do mercado de atuação, e no gerenciamento adequado do mix de marketing (4P's) (Kotler \& Keller, 2006). Segundo os autores, as estratégias são definidas baseando-se em Produto, Preço, Praça e Promoção, sendo assim definidas:

a) produto: é o produto físico ou o serviço oferecido aos consumidores pela empresa;

b) preço: existem várias estratégias para a definição de preço, as quais dependem do segmento de mercado a atingir, do perfil dos consumidores, do ambiente de negócios, aspectos culturais, da competição, entre outros fatores que podem comprometer os valores.

c) praça: analisa como o produto ou serviço será vendido e como chegará ao consumidor. Normalmente está associado aos canais de distribuição e a logística envolvida no processo de comercialização e apresenta grande importância, pois é através da distribuição que o cliente terá acesso aos produtos oferecidos.

d) promoção:apromoçãoestá relacionada com o processo de comunicação e de venda aos clientes potenciais. A promoção envolve propaganda e publicidade, relações públicas, diferentes tipos de mídias, feiras e eventos, patrocínios, entre outros pontos.

\section{Obtenção dos dados}

Os dados deste caso de ensino foram coletados através de entrevista semiestruturada, realizada com o gestor que administra o Centro de Assistência $\mathrm{SM}$, aqui retratado como o personagem do Sr. João Boll. Para a análise e a interpretação dos dados, o método utilizado foi a da Análise de Conteúdo, a qual consiste na utilização e verificação de elementos que permitem a apreciação das comunicações e fornecem 
informações suplementares para a compreensão da situação (Bardin, 2004). Para realização desta análise de conteúdo, buscou-se entender a história real da empresa desde a sua constituição, suas mudanças e seus diferentes posicionamentos ao longo dos anos e, a partir destes, inserir elementos fictícios para chamar a atenção do leitor para o caso.

\section{Referências}

ANDERSON, J., \& MARKIDES, C. (2007).

Strategic Innovation at the Base of the Economic Pyramid. Harvard Business On Line, 49(1), 83-88.

BARDIN, L. (2004). Análise de Conteúdo. Lisboa: Edições 70.

BARNEY, J. (1991). Firm resources and sustained competitive advantage, Journal of Management, 17(1), 99-120.

BASSO, K., LAIMER, C. G., \& BASEGGIO, H. W. (2015). Personalidade e boca-a-boca: Proposições de pesquisa. Revista Pensamento Contemporâneo em Administração, 9(2), 17-29.

BASSO, K., \& ESPARTEL, L. B. (2015). O uso de traços de personalidade para a diferenciação de consumidores em níveis de lealdade distintos. Contextus - Revista Contemporânea de Economia e Gestão, 13(1), 7-33.

BOONE, L. E., \& Kurtz, D. L. (1998). Marketing Contemporâneo. $8^{a}$ ed. Rio de Janeiro: LTC.

CHURCHILL, G. A. J., \& Peter, J. P. (2005). Marketing: criando valor para os clientes. 2 ed. São Paulo: Saraiva.

DE GUIMARÃES, J. C. F.; SEVERO, E. A.; DORION, E. C. H. (2014). Cleaner production and environmental sustainability: multiple case from serra gaúcha-Brazil. Espacios (Caracas), 35(4), 8.

DOS SANTOS, C. P.; Basso, K. (2012). Do ongoing relationships buffer the effects of service recovery on customers' trust and loyalty? International Journal of Bank Marketing, 30(3) 168-192.

DRUCKER, P. F. (2002). Administração na próxima sociedade, A-Exame. NBL Editora.

DRUCKER, P. F. (1984). The discipline of innovation. Harvard business review, 63(3), 67-72.
ETZEL, M. J., WALKER, B. J., \& STANTON, W. J. (2001). Marketing management. McGraw-Hill/Irwin, Boston, $M A$.

GUIMARÃES, J. C. F., SEVERO, E. A., VIEIRA, P. S. (2015). The relationship between innovation and sustainable competitive advantage: trajectory and challenges. Espacios (Caracas), v. 36, 1-16.

HAMEL, G. (1998). Strategy innovation and the quest for value. Sloan Management Review, 39(2), 7-14.

HURLEY R. F., \& HULT G. T. M. (1998).

Innovation, market orientation, and organizational learning: an integration and empirical examination. The Journal of Marketing, 62, 42-54.

JONES, T., \& SASSER Jr., W. (1995). Why satisfied customers defect? Harvard Business Review, 73(6), 8899.

KOTLER, P., \& KELLER, K. L. (2006) Administração de marketing. $12^{\mathrm{a}}$ ed. São Paulo: Pearson Prentice Hall.

LAMBIN, J. J. (1998). Marketing Estratégico. Lisboa: McGraw-Hill.

LAS CASAS, A. L. (2006). Plano de Marketing para Micro e Pequena Empresa. 4 ed. São Paulo: Atlas.

LIMA, M., SAPIRO, A., VILHENA, J. B., \& GANGANA, M. (2003). Gestão de Marketing.1.ed. Rio de Janeiro: FGV.

LOVERLOCK, C. (2006). Marketing de Serviços: pessoas, tecnologia e resultado. São Paulo: Pearson Prentice Hall.

MILLER, J. P. (2002). O Milênio da Inteligência Competitiva. Porto Alegre: Bookman.

OLIVER, R. L. (1997). Satisfaction: a behavioral perspective on the consumer. New York, NY: McGraw Hill.

PORTER, M. E. (1979). How competitive forces shape strategy. Harvard Business Review, 57(1), 86-93.

PORTER, M. E. (1990). The competitive advantage of nations; New York: The Free Press.

PORTER, M. E. (1989). Vantagem competitiva: criando e sustentando um desempenho superior. 15. ed. Rio de Janeiro: Campus.

REIS, C. O. O. (2000). O Estado e os planos de 
saúde no Brasil. Revista do Serviço Público, 51(1), 124147.

SCHUMPETER, J. A. (1982). A Teoria do desenvolvimento econômico. São Paulo: Editora Abril.

SCHUMPETER, J. A. (1934). The Theory of Economic Development. Cambridge, Massachusetts: Harvard University Press.

SEVERO, E. A. GUIMARÃES, J. C. F., DORION, E. C. H., NODARI, C. H. (2015) Cleaner production, environmental sustainability and organizational performance: an empirical study in the Brazilian metal-mechanic industry. Journal of Cleaner Production, 96,118-125.

SILVEIRA, H. (2001). Swot. In: Inteligência Organizacional e Competitiva. Org. Kira Tarapanoff. Brasília. Ed. UNB.

SIRDESHMUKH, D.; Singh, J.; Sabol, B. (2002). Consumer trust, value, and loyalty in relational exchanges. Journal of Marketing, v. 66, n. 1, p. 15-37, 2002.

TALKE, K., SALOMO, S., \& KOCK, A. (2011). Top Management Team Diversity and Strategic Innovation Orientation: The Relationship and Consequences for Innovativeness and Performance. Journal of Product Innovation Management, 28, 819-832.

WANG, C. L., \& AHMED, P. K. (2004). The development and validation of the organizational innovativeness construct using confirmatory factor analysis. European Journal of Innovation Management, 7 , 303-313.

WEBSTER Jr., F. E. (1994). Marketing-driven management: using new marketing concept to create a customer-oriented company. New York: John Wiley \& Sons.

WRIGHT, P., Kroll, J. M., \& Parmell J. (2000). Administração Estratégica. $1^{\mathrm{a}} \mathrm{ed}$. São Paulo: Atlas. 